\title{
British Paediatric Association
}

\section{Proceedings of the Fifty-first Annual Meeting}

The Annual Meeting of the British Paediatric Association was held at York from 27-31 March 1979. 410 members attended together with 3 Heinz Fellows, Observers from the Department of Health and Social Security, and the Scottish Home and Health Department, and 226 guests. The George Frederic Still Memorial Lecture was given by Prof. R. J. Haggerty (Harvard School of Public Health). Three speakers from developing countries gave lectures at a session on Deprivation organised to commemorate the International Year of the Child.

The Annual General Meeting of the British Paediatric Association was held on Thursday, 29 March 1979. The President, Prof. O. H. Wolff, was in the chair.

The minutes of the last meeting, which had been published in the Archives of Disease in Childhood, were received and approved.

ELECTION OF OFFICERS. The following were elected. PRESIDENT: $\quad$ Dr G. M. Komrower HONORARY SECRETARY: Dr D. R. Harvey HONORARY ASSISTANT SECRETARY: $\quad$ Dr C. H. Nourse

MEMBERS OF COUNCIL 1979-82: Dr D. P. Addy, Dr J. D. Andrew, Prof. F. Cockburn, Dr B. W. Lewis, Dr L. Rosenbloom, Dr H. B. Valman, Dr S. G. F. Wilson.

HONORARY MEMBERs: Prof. H. Ali Khan, Dr N. Kretchmer, Dr R. Whitehead.

MEMBERS: C. J. Bacon (Northallerton), S. E. Barnes (Salisbury), N. R. Belton (Edinburgh), J. W. T. Benson (Liverpool), D. Bentley (London), I. Blumenthal (Bradford), J. G. Bissenden (Birmingham), R. L. Broadhead (Manchester), D. S. K. Brookfield (Southampton), L. P. Carroll (Leicester), D. J. Carson (Craigavon), I. Chalmers (Oxford), P. Congdon (Leeds), K. D. Connolly (Ballinasloe), Jennifer M. Cowen (Liverpool), J. G. Davies (Birmingham), Blanche M. Dawson (Aberdeen), Ruth E. Day (Glasgow), B. Denham (Dublin), J. F. Dossetor (Glasgow), E. J. Eastham (Newcastle), D. R. Evans (Cardiff), P. J. Fleming (Bristol), Sally E. Flew (Hounslow), Patricia
Franklyn (Bradford), Eva A. Frommer (London), D. C. Gordon-Nesbitt (Manchester), Elizabeth Griffin (Dublin), D. Hall (London), C. P. Hallett (Bury), Katherine A. Hallidie-Smith (London), O. J. Hanmer (Aberdeen), R. F. Harris (Wegberg), J. Z. Heckmatt (Leeds), G. M. A. Hendry (Edinburgh), Elaine M. Hicks (Belfast), Marion Hommers (Coventry), I. A. Hughes (Cardiff), J. C. Hyde (London), Susan J. Ilett (Sheffield), J. G. Jenkins (Belfast), R. F. Joanes (Stourbridge), R. Leanage (London), R. J. Levinsky (London), J. MacKinnon (London), P. Manuel (London), Carol P. Millns (Lincoln), I. Mitchell (Airdrie), C. J. Morley (Manchester), Anne Murphy (Louth), C. S. Nelson (Glasgow), J. H. Nirmal (Hartlepool), A. Oakhill (Birmingham), J. P. Osborne (Bristol), G. G. Owens (Liverpool), Barbara Phillips (Manchester), L. Polnay (Nottingham), F. N. Porter (Aberdeen), C. J. Rolles (Southampton), M. Joyce Rubissow (Birmingham), N. Rutter (Nottingham), O. Smales (Nottingham), M. L. Smith (Derby), Olga Stark (London), Ann L. Stewart (London), J. K. Stothers (London), I. L. Swann (Cardiff), Joan M. Tarnoky (Reading), Vivian V. Tracey (Northampton), R. S. Trompeter (London), Shelagh Tyrrell (London), J. Wagget (Newcastle), J. G. Watson (London), R. W. Watt (Wigan), Marjorie E. Watts (London), A. R. Wilkinson (Oxford), M. J. H. Williams (London), M. L. N. Willoughby (Glasgow), Vanessa M. Wright (London), T. D. Yuille (Bristol).

\section{Report of the Council 1978-79}

\section{OBITUARIES}

The Association has suffered the loss of Dr L. O. Abeyaratne, Prof. R. Debré (Honorary Members), Dr C. K. J. Hamilton (Original and Honorary Member), Prof. A. Holzel (Honorary Member), Dr R. J. Isaacs, Dr W. W. Payne (Honorary Member), Prof. H. Valquist (Honorary Member), and Dr H. Parry Williams.

\section{DISTINCTIONS}

Council has noted with great pleasure that Prof. F. S. W. Brimblecombe has been appointed first chairman of the Joint Committee for Children; Prof. S. D. M. Court has been awarded the Rosen 
von Rosenstein Medal for 1979; Dr D. Gairdner has been awarded the 1978 Dawson Williams Memorial Prize, Dr H. Jolly the Medical Journalists Award for 1978, and Dr E. M. Widdowson the CBE.

\section{COUNCIL}

Membership. The following members of the Association have served on Council during 1978-79: Prof. O. H. Wolff (President), Dr E. H. Back, Dr R. D. H. Boyd (Honorary Assistant Secretary), Dr C. G. D. Brook, Dr A. F. Conchie, Dr Barbara Davies, Dr W. Davies, Prof. E. E. Doyle, Dr D. W. Fielding, Dr C. A. S. Galloway, Dr J. R. Harper, Dr A. D. M. Jackson (Honorary Treasurer), Dr G. M. Komrower (President Elect), Dr Sheila Lewis, Dr M. M. Liberman (Honorary Assistant Secretary), Dr J. M. Littlewood, Prof. June K. Lloyd (Honorary Secretary), Dr D. Morris, Dr T. C. Noble, Dr C. H. Nourse (Honorary Assistant Secretary), Dr Aileen Redmond, Dr N. J. Royston, Dr R. A. Shanks, Dr M. J. Simpkiss, Dr H. Simpson, Dr P. E. Walker, Dr B. Wolman, Dr M. H. Bellman (Junior Representative), Prof. D. Hull (Chairman of the Academic Board).

Observers. The Association is grateful to the following for assistance and advice both at Council and in many other ways: Dr Margaret Bell (Scottish Home and Health Department), Prof. F. S. W. Brimblecombe (Member of the Central Health Services Council), Mr A. Jolleys (President of the British Association of Paediatric Surgeons), Prof. T. E. Oppé (Adviser in Child Health, DHSS), Dr Marie Richards (Welsh Office), and Dr Esther Simpson (Department of Health and Social Security).

Meetings. Council met on three occasions: 13 May and 14 October 1978, and 10 February 1979.

\section{MATTERS CONCERNING THE ADMINISTRATION OF THE ASSOCIATION}

The Association's permanent staff continues to comprise an Executive Secretary and three Assistant Secretaries. It was necessary to take on a temporary secretary for the two months before the 1979 Annual General Meeting to process the booking forms.

The Association would like to record its continuing debt of gratitude to the Institute of Child Health for portering and mailing services, and the use of duplicating facilities and rooms for meetings.

Academic Board. The 13th Annual Report of the Board has been received by Council.

\section{AWARDS OF THE ASSOCIATION}

James Spence Medal-Prof. Kenneth Cross.

Donald Paterson Prize-Dr R. J. Levinsky.

Heinz Fellowships for 1979-80-Dr M. B. Abdurrahman, Prof. Mrs M. M. Mehta, and Dr S. K. Sen (Fellowship A); Dr C. D. Moyes, Dr A. J. R. Waterston, and Dr R. J. West (Fellowship C). Council is continuingly grateful to H. J. Heinz and Company for their valuable support. The Association remains indebted to the Nuffield Foundation for their advice and administrative help.

\section{FINANCE AND ALLIED MATTERS}

The Directors of Unigate have again generously donated their annual travel grant of $£ 225$ and have supplied the programme and all stationery for the 1979 Annual General Meeting.

The BPA continues to benefit by a share of the profits from the sale of the Archives of Disease in Childhood.

\section{MEETINGS OF THE ASSOCIATION}

The 50th anniversary meeting of the Association was held at York in April 1978. 639 members and guests attended. A special anniversary meeting and dinner was held in London on 7 July 1978. 168 members and guests attended.

Council wishes to record its appreciation to the Academic Board in organising the scientific programme for these meetings and to thank the many members and guests who submitted papers. Council also wishes to thank the conveners and members of specialty groups (12 of which held sessions during the meeting) for their contributions.

The next Annual Meeting of the Association will be held from 15-19 April 1980.

\section{STANDING COMMITTEES AND WORKING PARTIES} OF THE ASSOCIATION

Reports have been received by Council, and comments have been submitted to government departments and other bodies on many important issues.

This has been a particularly busy year for the Association and Council is deeply grateful to the members who served on committees and working parties and also to those who represented the Association on both statutory and voluntary bodies. Many individual members have helped the Association by their advice, suggestions, and criticisms.

Council wishes to record its special appreciation of the work of the Editors of the Archives of Disease in Childhood; the journal continues to be of the greatest value to British paediatrics. 


\section{Other agenda items}

1. Dr C. H. M. Walker outlined the work of the BPA Health Statistics Sub-committee during 1978 both in the preparation of the BPA International Classification of Diseases and its involvement with the Child Health Computing Committee of the DHSS currently investigating methods of medical data storage.

2. The meeting approved the establishment of a category of Associate Membership for Senior Clinical Medical Officers and Clinical Medical Officers whose work is mainly in the field of child health.

\section{SCIENTIFIC PROCEEDINGS}

GEORGE FREDERIC STILL LECTURE. The lecture was delivered by Prof. R. J. Haggerty, Roger Irving Lee Professor of Public Health, Harvard School of Public Health, Boston, on 'Life stress, social support, and health'.

\section{National Childhood Encephalopathy Study-a} preliminary report. M. H. Bellman, D. L. Miller, P. D. Poore, and E. M. Ross. London.

The National Childhood Encephalopathy Study seeks to assess the relative risk of serious neurological disorders, associated with immunisation, in young children. It also attempts to identify other factors that may cause or predispose to the development of such disorders in immunised and unimmunised children.

A case control analysis was carried out on children between ages 2 months and 3 years admitted to hospital with a defined group of clinical conditions.

In the first year 258 cases were identified. The most common diagnoses were febrile convulsions $(34 \%)$, encephalitis $(26 \%)$, and infantile spasms (15\%). There was no constant aetiological pattern and in only $10(4 \%)$ cases was the cause clear. The sex ratio was approximately equal, and the age distribution shows a peak at 6 months, with a gradual decline during the next $2 \frac{1}{2}$ years. Comparing cases with controls there was no significant difference in the proportion of children immunised within the period of 28 days before admission.

Preliminary results have not identified a significant association between encephalopathy in children and recent immunisation. Although a clinical diagnosis can often be made, there remains a group of children in whom the causal factors and classification of neurological disorder is obscure.
A study of heart rate and rhythm in normal schoolchildren. P. G. B. Johnston, F. Johnston, J. M. Richards, E. A. Shinebourne, and D. P. Southall. Dorchester.

Cardiac arrhythmias associated with sinus node dysfunction have been suggested as a cause of fits, faints, and 'funny turns' in childhood. However information on normal heart rate and rhythm is poorly documented and therefore single 24-hour ECG recordings were performed on 90 randomly selected healthy 7- to 11-year-old children. The mean highest heart rate over 9 beats was $164 \pm 16$, the mean lowest heart rates were $49 \pm 6$ over 3 beats and $56 \pm 6$ over 9 beats' duration. At their lowest heart rates $42(46 \%)$ had intermittent junctional rhythms. One child had episodes of complete 2:1 and Wenckebach A-V nodal block and 7 had intermittent prolongation of the PR interval $(>0 \cdot 20$ seconds). 19 had isolated atrial premature beats. In a randomly selected subgroup of 29 children, $23(79 \%)$ had sinoatrial Wenckebach block and $5(17 \%)$ had 2:1 sinoatrial block patterns.

A history and clinical examination was taken on all children studied and this showed no correlation between variations in rhythm and rate and clinical findings. This study demonstrates that normal children exhibit variations in heart rate and rhythm hitherto considered to be abnormal, and therefore normal data must be carefully considered before making a diagnosis of conducting system disorders such as the sick sinus syndrome.

A follow up study of disturbed 3-year olds. P. J. Graham, N. Richman, and J. Stevenson. London.

A total population of 3-year-old children were screened for behaviour disturbance using a standardised procedure of known reliability and validity. Approximately 100 children were identified as showing significant problems and these were matched by sex and social class with a similar number of control children. These children were followed up at 4 and 8 years. Over $90 \%$ of the mothers were interviewed at 8 years.

There was a considerable amount of continuity. At 8 years $62 \%$ of the 3-year problem group were still disturbed compared with $22 \%$ of the controlsa highly significant difference. Independent ratings made by fathers and teachers confirmed that continuity was not merely a function of the mother's perception of the child as disturbed. Family relationships and maternal mental health at 3 years were not good predictors of behavioural outcome at 8 years. Few of the disturbed 8-year olds had been in receipt of any form of professional service. 
Findings were discussed in relation to prediction and possible preventive measures for, despite the high level of continuity, only about one-third of disturbed 8-year olds would have been identified on the basis of disturbance at 3 years.

Longitudinal study of overweight children and young adults in the national survey of health and development. O. Stark, E. Atkins, and O. H. Wolff. London.

From the original population of 13687 children born in one week in March 1946 a cohort of 5362 has been followed at regular intervals. Weights and heights are available at ages $2,4,6,7,11,15,20$, and 26 years. A power-type index of weight for height, age, and sex was used as a 'standard' for calculation of percentage overweight and underweight. The prevalence of overweight (defined as $>20 \%$ above standard) was 1.6 and $2.8 \%$ for males and females respectively at 6 years; 2.0 and $3.7 \%$ at 7 years; 6.7 and $9.6 \%$ at 11 years; 6.6 and $9.6 \%$ at $14 \frac{1}{2}$ years; 5.3 and $6.6 \%$ at 20 years; and 12.8 and $11.5 \%$ at 26 years. Three-quarters of girls and nearly half the boys who were overweight at 6 years were overweight at 26 years and various patterns were noted in the evolution of overweight from childhood to adulthood. In general the risk of being overweight in adulthood increased with the degree of overweight present in childhood. The degree of overweight changed gradually with time so that it exhibited greater stability in the short term than over longer periods.

The correlation between relative weight status in adult life and childhood increases as the child gets older; thus only $10 \%$ of the overweight 26 -yearold women had been overweight at age 6 years, and this percentage rises to $45 \%$ at $14 \frac{1}{2}$ years. The corresponding percentages for men are 6 and $28 \%$.

Effects of supplementary vitamin D during pregnancy on Asian women and their infants. O. G. Brooke, C. Bone, I. R. F. Brown, N. D. Carter, D. Maxwell, and V. Robinson. London.

Pregnant Asian women have lower blood levels of vitamin D than Europeans (Dent and Smith, 1969) and their infants are prone to hypocalcaemia (Watney, 1975) and neonatal rickets (Ford et al., 1973). We therefore investigated the effect of vitamin D supplements during pregnancy in a group of Asian women and their infants. Ergocalciferol, $1000 \mathrm{IU} /$ day, or placebo were given by random allocation to 61 Asians during the last trimester. The trial was double blind. Blood calcium, phos- phate, alkaline phosphatase, 25-hydroxycholecalciferol (25-OHD), and vitamin D binding globulin (VDBG) were measured on entry to the trial, after delivery, and in cord blood. Infant blood calcium was measured on day 3 and 6, and fetal growth was assessed by anthropometry. The following results were obtained. (1) Mean plasma 25-OHD declined in late pregnancy in the control group and was very low in cord and postpartum blood (9 and $12 \mathrm{nmol} / 1$ respectively). (2) The treated group had significantly higher mean plasma 25-OHD in cord and postpartum blood (110 and $153 \mathrm{nmol} / \mathrm{l})$. (3) There was a positive correlation between maternal and cord blood 25-OHD $(r=0.92, P<0.001)$. (4) Alkaline phosphatase levels were lower in the treated than the control group, both in maternal and cord blood $(P<0.05)$. (5) There was no difference between treated and control groups in fetal growth, neonatal calcium levels, or maternal and infant VDBG levels.

We conclude that, while vitamin $D$ supplements may be necessary in Asians to prevent deficiency during pregnancy, they do not influence fetal growth or neonatal calcium levels.

\section{References}

Dent, C. E., and Smith, R. (1969). Nutritional osteomalacia. Quarterly Journal of Medicine, 38, 195-209.

Ford, J. A., Davidson, D. C., McIntosh, W. B., Fyfe, W. M., and Dunnigan, M. G. (1973). Neonatal rickets in Asian immigrant population. British Medical Journal, 3, 211-212.

Watney, P. J. M. (1975). Maternal factors in the aetiology of neonatal hypocalcaemia. Postgraduate Medical Journal, 51, Supplement 3, 14-17.

What can be expected from growth hormone therapy? W. Hamilton. Glasgow.

The clearance rate of administered human growth hormone (hGH(UK)) was studied in 12 children who were receiving $\mathrm{hGH}(\mathrm{UK})$ for short stature due to isolated growth hormone deficiency.

Administration of hGH stimulates a rise in plasma cortisol, and gives an 'effective' plasma level of hGH from 2.5 to $6 \mathrm{~h}$ postinjection. The high level of plasma oestradiol suggests that administered hGH (or an impurity) stimulates ovarian function. Likewise the levels of T3 and T4 with a normal TSH level suggests possible chronic thyroid stimulation from the hGH.

These findings stimulated an analysis of the clinical data on 29 children treated with hGH for short stature over 2 to 4 years. Only 2 boys out of 20 crossed the 3rd centile upwards; 18 did not increase significantly their growth velocity. When height was charted in relation to bone age, bone age accelerated faster than increments in height were obtained. Similar findings were observed in 9 girls (charts available). 
These data suggest that hGH (or an impurity) accelerates osseous maturation, either via thyroid or gonadal stimulation, to a greater degree than it increases linear growth.

The physical, biochemical, and immunological status of hGH(UK) was therefore defined. The conclusions are that $\mathrm{hGH}(\mathrm{UK})$ contains up to $50 \%$ polymer (likely to reduce total growth stimulating effects) and a measurable amount of both LH and FSH (stimulants of gonadal activity). The net effects predictable therefore are early osseous fusion (from gonadal stimulation) and a restriction in the rate of linear growth (only $50 \%$ of the dose administered effective). Thus it can be expected that ultimate short stature (in most cases less than 3rd centile) is likely to result from the treatment of patients with short stature with hGH(UK).

Temperature control in incubators. J. K. Stothers and $\mathrm{K}$. W. Cross. London.

Abdominal skin temperature is commonly used to govern the environmental temperature in servocontrolled incubators. Ill babies are frequently nursed prone, thus insulating the abdomen, rendering it thermally unresponsive to external temperature change and unrepresentative of general surface temperature which governs sensory input and response.

It therefore seemed desirable to find a site responsive to environmental temperature change and representative of mean skin temperature. Both thermographic (Clark et al., 1978) and thermocouple measuring systems were used. The infants were nursed prone in a Vickers incubator (model 79) while temperatures were recorded at 9 sites using the thermocouple thermometer. When possible, infrared thermograms were filmed simultaneously.

Both methods gave similar values of mean skin temperatures, and the upper arm and thigh were found to approximate closely to the mean. In addition, they responded well to environmental temperature changes.

These findings suggest that if incubators are to be used in the servo mode, and this is in itself questionable, the above sites would be more suitable for sensor placement than the insulated abdominal skin of the prone infant.

\section{Reference}

Clark, R. P., Cross, K. W., Goff, M. R., Mullan, B. J., Stothers, J. K., and Warner, R. M. (1978). Neonatal whole-body thermography. Journal of Physiology, 280, 2P-3P.
Early diagnosis of group B streptococcal disease in the newborn. M. J. Lewins and J. Dodge. Cardiff.

A review of 14 infants admitted to the neonatal intensive care unit of the Hospital for Sick Children, Toronto, with early group B streptococcal (GBS) disease demonstrated the difficulty of establishing a clinical diagnosis from the history, examination, and chest $x$-ray. All infants were initially diagnosed as having respiratory distress syndrome (RDS).

Nine of these infants died. All infants who had apnoeic episodes before antibiotic therapy died. Those infants who survived received antibiotics at a significantly earlier age but were otherwise similar to the group who died.

In a subsequent prospective study, all infants admitted with a provisional diagnosis of RDS had their gastric contents aspirated and the aspirate subjected to culture, Gram staining, and a 'shake test' for surfactant activity. All the infants also had blood cultures and differential white cell counts. All received antibiotics. In this time 6 infants were identified as having GBS within an hour of admission. Four of these infants survived.

It is concluded that these methods offer the opportunity for early clinical diagnosis of GBS and, with early antibiotic therapy, may reduce mortality from the disease.

Prevention of thalassaemia major by antenatal diagnosis. B. Modell, M. A. Angastiniotis, D. V. I. Fairweather, M. Matzabio, and R. H. T. Ward. London.

Prevention of thalassaemia major by antenatal diagnosis, using fetal blood samples obtained at 18-22 weeks' gestation, is now an established procedure: 170 cases have been managed at UCH. There are 2 methods for fetal blood sampling: blind needling of the placenta carries a $7 \%$ risk of immediate intrauterine death, while fetoscopy, with fetal blood sampling, appears to carry a $15-20 \%$ risk of premature labour with its attendant problems. There is an approximately $1 \%$ risk of laboratory misdiagnosis-that is, confusion between thalassaemia major and thalassaemia trait. As married couples at risk for thalassaemia major infants can be detected before they have had an affected child, such couples should now be sought in the antenatal clinic (and possibly before they reach this stage), so that they can receive genetic counselling and consider the offer of antenatal diagnosis. The response of atrisk couples to this offer differs widely between the two affected communities in Britain. Nearly $100 \%$ of Cypriots request antenatal diagnosis, while about 
$60 \%$ of Indian/Pakistani couples do so. This cultural contrast gives some guidance about the most desirable methods of screening populations for carriers. This work has wider implications in that it provides a small-scale model for the attitudes and requirements of the British population when antenatal diagnosis for endemic common inherited diseases, such as fibrocystic disease and phenylketonuria becomes available, as is likely in the next few years.

Problems of antenatal screening of a total population for neural tube malformations. $K$. M. Laurence, K. Evans, B. Hibbard, and C. J. Roberts. Cardiff.

Although the collaborative survey shows that prenatal detection using serum alphafeto protein estimated at 16-18 weeks is feasible, the problems of introducing and conducting a population screening programme have not been identified. A screening programme was set up, based onall the pregnancies in mid-Glamorgan from 1977 to investigate the problem. The following comments are based on the first 3330 completed pregnancies by the end of the first 6 months.

Successful population screening depends on a good laboratory, genetic counselling, transport, communication and co-operation with staff, and compliance of the mothers. An efficient supraregional radioimmunoassay laboratory is essential. Genetic counselling services have to cope not only with preamniocentesis and pre- and postabortion counselling, but also with the other problems coming to light during screening. Efficient transport of specimens to the laboratory and reports back to the clinics and consultants is essential. Communication between clinics, laboratory, obstetricians, GPs, genetic clinics, etc., is vital. Good compliance of patients' understanding the aims of screening, attending early enough for this to be instituted, and GPs being co-operative and referring early enough to the clinic, is one key to success. An efficient ultrasound to date pregnancies accurately and competent amniocentesis with few sequential abortions are essential. With serum samples taken between 16 and 18 weeks, amniocentesis tends to be carried out when discrimination between normal and abnormal AFP values become blurred. This leads to possible problems of both false-positive and negative. Obstetricians sometimes deviate from usual procedures which may also lead to tragedy.

Well conducted screening can reduce the number of babies with neural tube malformations reaching term to less than $10 \%$, leading to a considerable saving of paediatric resources and prevention of much family anguish.
Diagnosis of vesico-ureteric reflux without bladder catheterisation. S. T. Meller, H. B. Eckstein, and B. C. H. Ward. Carshalton.

The method of indirect radionuclide cystography (RNC) is described. The urinary tract is imaged with a gamma camera after intravenous administration of a technetium-labelled chelate. When the bladder is full the child is required to void on request. Reflux which reaches the renal pelvis will generally be recognised from the analogue gamma camera images. Using a small computer to store digital images and to generate time/activity curves from the kidneys and bladder improves the diagnostic accuracy. Spontaneous reflux during bladder filling may also be recognised.

25 children, aged 3 to 12 years, first had standard radiological investigation - an intravenous urogram and micturating cystourethrogram (MCU)-and were then referred for RNC. They were examined by one observer without prior knowledge of the radiological findings. Six children were unable to void on request. Three studies were spoiled by movement artefact. In 14 examinations (23 normal units and 5 refluxing units) the MCU and RNC proved to be in accord. In 2 cases there were conflicting results.

The RNC avoids the trauma of bladder catheterisation and provides a physiological approach to the diagnosis of reflux. The radiation exposure is significantly reduced. We recommend the use of this technique in selected cases.

Renal growth following unilateral antireflux surgery. J. D. Atwell and P. Cox. Southampton.

112 children treated surgically for unilateral vesicoureteric reflux at the Wessex Regional Centre between 1969 and 1975 were reviewed. The ages of the patients ranged from one month to 13 years and the mean length of follow-up was 3 years 11 months. Renal growth was assessed in each patient by measurements of renal length from serial intravenous pyelograms performed preoperatively and at intervals during the period of follow up.

Calculations of the mean renal lengths preoperatively and at 3 months, 1 year, and 5 years postoperatively suggest that renal growth accelerates after successful reimplantation of the ureter. The phase of rapid renal growth was confined to the first postoperative year and is greatest in the first 3 months after antireflux surgery and was equal in both kidneys. The mechanisms accounting for these alterations in renal growth remain obscure. 
Adhesion of Enterobacteriaceae to buccal epithelial cells. D. Candy, J. T. Harries, T. S. M. Leung, W. C. Marshall, and A. Phillips. London.

The pathophysiology of infantile diarrhoea is currently under intense investigation particularly in relation to adhesion of bacteria to the alimentary tract, which we have studied using human buccal epithelial cells (BEC).

A pathogenic strain of Escherichia coli (O26:K60) known to adhere to human fetal intestine (McNeish et al., 1975) adhered to adult BEC, while a nonpathogenic, nonadhesive strain $(\mathrm{O} 1: \mathrm{K} 1)$ did not. Adhesion was temperature-dependent, correlated with fimbriae production, and was inhibited by breast milk. Serotypable $E$. coli from stools of 7 infants with acute diarrhoea, and $E$. coli, Enterobacter sp., Proteus sp. (and Candida albicans) from the small intestine of 3 infants with protracted diarrhoea, adhered to BEC from $6 / 7$ and $3 / 3$ of the infants' BEC respectively. The nonadhesive $E$. coli (O1:K1) adhered to BEC from the latter group. Adhesion of all Enterobacteriaceae was inhibited by D-mannose.

Our results indicate that BEC provide a simple model for studying intestinal adhesion of bacteria in man, and suggest that adhesion may be mediated by mannose-like receptors. Moreover, the test system has the important advantage that bacteria can be studied with cells from affected cases, and thus may provide a means of assessing the "enteropathogenicity' of bacteria in individual patients.

\section{Reference}

McNeish, A. S., Turner, P., Fleming, J., and Evans, N. (1975). Mucosal adherence of human enteropathogenic Escherichia coli. Lancet, 2, 946-948.

A spoonful of sugar helps the medicine go down. I. F. Roberts and G. Roberts. London.

The aim of this study was to see if chronic administration of liquid medicines sweetened with sucrose had a deleterious effect on children's teeth. The teeth of a group of 44 children aged less than 6 years who had been taking syrup medicines regularly for at least 6 months were compared with those of a control group of 47 children of similar ages. Dental decay was assessed, using established dental formulae, by measuring their carious index, plaque index, and gingival index. The dentist's ability to be consistent in his measurement of dental decay was checked by performing repeatability tests; analysis of these using the Spearman's rank correlation coefficient indicated that the clinical findings were sufficiently reliable for the purpose of this study. A questionnaire, related to other factors known to children's deciduous teeth was completed at the end of each dental examination.

The children who received sucrose-based medicine had more carious teeth $(P<0.05)$ and more gingivitis $(P<0.05$, Mann-Whitney $U$ test). Information obtained from the questionnaire was analysed using the $\chi^{2}$ test, and showed no difference between the two groups for cariogenic factors unrelated to medicines.

It is concluded that sucrose-based medicine regularly administered to children for 6 months cause dental caries and gingivitis. Liquid medicines for children should therefore be either unsweetened or sweetened with noncariogenic substances.

A comparison of intellectual abilities following treatment for leukaemia and solid tumours during childhood. C. Eiser. London. To be published in full in the Archives, 1980, 55.

Bone marrow relapse on treatment in childhood acute lymphoblastic leukaemia. J. James, J. H. Baumer, B. Howlett, P. J. Kearney, and M. G. Mott. Bristol.

A retrospective study was carried out on children with acute lymphoblastic leukaemia having their first relapse in the bone marrow while on treatment. Among 190 children from 9 major centres in the United Kingdom, there were no long-term survivors. The median durations of complete and haematological remission were 80 and 97 days respectively. The risk of developing meningeal leukaemia in the second remission was $46.1 \%$ and for overt testicular infiltration in boys was $15.7 \%$. The main factor at diagnosis affecting outcome was the initial total white blood count. Children with a high white count relapsed earlier while on treatment and survived for a shorter period of time after relapse, with shorter duration of the second remission. They achieved a second remission as readily as children with low initial white blood counts. These effects appeared to be dependent on the T-cell status of the leukaemia.

There was a group of children in whom a first remission was achieved only with difficulty, who were particularly resistant to treatment after relapse. The majority of children who attained a second remission did so within 12 weeks of relapse. There were a few children who survived for periods up to one year in relapse, however. Children who had not received vincristine and prednisolone as maintenance therapy before relapse were more likely to achieve a second remission. Those children who were 
resistant to the more commonly used drugs also appeared to be resistant to other groups of drugs. We conclude that children who end their first remission with relapse in their bone marrow while still receiving treatment are not curable by present chemotherapeutic regimens. Any attempt at improving this situation (for example, by bone marrow transplant) will need to take account of the high risk of CNS leukaemia subsequently developing in these children.

A special session on Deprivation was organised to commemorate the International Year of the Child

Deprivation in London: social and economic factors. N. D. Deakin.

Individual differences and protective factors in children's responses to deprivation. M. L. Rutter.

Child growth, malnutrition, and deprivation. $L$. Mata.

Family size and deprivation in the UK. D. Greaves. Identifying community resources and using themrural Maharashtra; some interventions. R. S. Arole.

British Paediatric Tropical Child Health and Community Paediatric Groups-Combined Session.

Organisation of rural maternal and child health services in Tanzania. W. Madundo.

A profile of infant growth and health in inner city deprivation. J. P. Stanfield.

Problems and strategies in the management of deprivation in preschool children. J. W. Partridge. The changing pattern of infant deaths in Sheffield 1968-77. R. Sunderland.

Volume and composition determination of suckled breast milk. A. Lucas.

Amenorrhoea in the deprivation syndrome. D. MacCarthy.

\section{POSTER PRESENTATIONS}

Errors in the diagnosis of child abuse. M. W. Arthurton and M. F. G. Buchanan.

Diarrhoea and measles in Tanzanian children. D. S. K. Brookfield, E. J. Bell, B. P. Gosgrove, and C. R. Madeley.

Pattern of jaundice in term infants over a 5-year period. K. Costeloe, J. D. Baum, and D. Hill.

When should babies be sent home from SCBUs? D. P. Davies, V. Haxby, and A. S. McNeish.

Age-dependent changes in lymphatic response during the neonatal period. E. J. Guiney, P. Blake, $O$. Browne, O. Hensey, N. O'Brien, P. Puri, and D. J. Reen.
Congenital complete heart block in the newborn associated with maternal systemic lupus erythematosus and other connective tissue disorders. J. D. Hardy, G. S. Banwell, R. Beach, F. Howard, S. Solomon, and V. Wright. Published in full in the Archives, 1979, 54, 7-13.

Plasma 25 hydroxy vitamin $D$ in pregnant Asian mothers and their babies. J. Z. Heckmatt, A. E. J. Davies, J. McMurray, and M. Peacock.

'Anaemia' with a 'normal' haemoglobin concentration: iron deficiency in cyanotic congenital heart disease. B. M. Holland, R. D. Hutton, C. Scott, A. Veale, and C. A. J. Wardrop.

Salt and sugar measure in the management of diarrhoea. P. Hutchins, J. Broomhall, and D. Morley. Vitamin $\mathbf{E}$ and growth in the low birthweight neonate. M. I. Levene.

Drug use in preterm and term babies. T. A. Moreland and G. W. Rylance.

Stature and the family. C. D. Moyes.

Nine years old in London. M. Pollak.

Assessment of the short-term results of bile-drainage operations in extrahepatic biliary atresia (EHBA). H. T. Psacharopoulos, E. R. Howard, and A. P. Mowat.

Child Development Centre data: collection and usage. R. E. Pugh and L. Rosenbloom.

Origins of childhood handicap. M. Radford and C. E. M. Jones.

Drug availability and dosage information for children. G. W. Rylance.

Intubation practice in maternity hospital. R. H. Schwartz, J. D. Baum, and R. M. Gardiner.

Child health records and the computer. C. H. M. Walker and the BPA Health Statistics Sub-committee.

What causes kwashiorkor in the older child? A. J. R. Waterston.

Transpyloric feeding in very low birthweight infants. M. F. Whitfield.

Ultraviolet light and vitamin D status in epileptic children. M. Davie, J. L. Barnes, N. D. Barnes, and G. E. Roberts.

\section{GROUP SESSIONS}

\section{British Paediatric Cardiology Section}

Dopamine infusion-improved therapy for persistent transitional circulation. G. I. Fiddler. 
A new approach to the treatment of transposition of the great arteries. R. C. Radley-Smith.

Exercise studies in children with transposition of the great arteries after Mustard operation. P. Weller.

Congenital heart disease and parental consanguinity in Asians. A. R. Gathrad.

Aortopulmonary window and associated anomalies: diagnosis and management. K. C. Lau.

Management and result of surgery in symptomatic infants with coarctation of the aorta. Susanna M. Hart.

Intracardiac electrophysiological studies in the assessment and management of cardiac arrhythmias in children. P. V. L. Curry.

\section{British Paediatric Immunology Group}

Four families with immunodeficiency and chromosome abnormalities. D. Candy.

Effects of sera from children with Crohn's disease on lymphocyte transformation in vitro. P. Hindocha.

Exudative response to milk and other proteins. Lynn Alexander.

Malnutrition, antibodies, and parasitic infestation in the tropics. F. Carswell.

A successful graft from an unrelated donor into an infant with SCID disease. K. Hugh Jones.

Purine studies in an infant with adenosine deaminase deficient severe combined immune deficiency. J. G. Watson.

Immunodeficiency secondary to enteropathic disorders. P. Hindocha.

Delayed separation of the cord and defective neutrophil mobility. Mary C. Greenwood.

Immunological aspects of appendicitis and abdominal pain in children. N. V. Doraiswamy.

A bacteriocidal polypeptide in amniotic fluid. C. M. M. Stern.

\section{British Paediatric Neurology Association}

Long-term outcome of some neurological diseases of childhood

Duchenne muscular dystrophy (DMD) and spinal muscular atrophy (SMA): prognosis and prevention. D. Gardner-Medwin.

Milestones on the downward path in the progressive degenerative brain diseases. E. M. Brett.

Childhood brain tumours-results of therapy and long-term problems. C. C. Bailey.

Long-term outcome of febrile convulsions. Sheila $\mathbf{J}$. Wallace.

Basilar migraine in childhood. Judith M. Hockaday. Opitz syndrome (hypertelorism hypospadias dull normal intelligence). N. J. O'Doherty.
Neuropathic bladder in spinal dysraphism. Malgorzata Borzyskowski.

Role of viruses in febrile convulsions. Helen Lewis. Published in full in the Archives, 1979, 54, 869-876. Metabolic effects of ketogenic diets in the treatment of children with epilepsy. Ruby Schwartz.

Carrier detection in Duchenne muscular dystrophy. J. R. Sibert. Published in full in the Archives, 1979, 54, 534-537.

\section{British Paediatric Nutrition, Metabolism, and Pharma- cology Group}

Biotin-responsive developmental deterioration and alopecia. L. S. Taitz.

Dietary treatment of 7 patients with homocytinuria treated from the newborn period. I. B. Sardharwalla. Treatment of Hurler's disease (mucopolysaccharidosis IH: congenital $\alpha$-iduronidase deficiency) by fibroblast transplant. Dorothy A. Gibbs.

Use of urinary lactate estimations in disorders associated with a lactic acidosis. D. B. Dunger.

Effect of the provision of school milk on the growth of schoolchildren. I. A. Baker.

Assessment of carbamazepine dose-frequency regimens in children. G. W. Rylance.

Salivary theophylline levels in the management of asthmatic children. S. M. Lena.

Naloxone kinetics in the newborn after IV and IM administration. T. A. Moreland.

\section{British Society of Paediatric Endocrinology}

Experience of screening for congenital hypothyroidism. J. A. Hulse.

A system for diagnosis of neonatal hypothyroidism.

Sarah J. Bodden.

Screening for congenital hypothyroidism-does it have a place in the UK? N. D. Barnes.

Hormonal and auxologic patterns in boys with constitutional growth delay. J. L. Penfold.

Growth response to GH therapy in children with radiation-induced GH deficiency. S. M. Shalet.

Familial male pseudohermaphroditism due to $5 \alpha-$ reductase deficiency. M. O. Savage.

Prognosis of the Prader-Willi syndrome. B. M. Laurance.

Monitoring of serum prednisolone levels in patients with renal disease by solid phase radioimmunoassay (RIA). B. T. Rudd.

Congenital adrenal hyperplasia: are we detecting male salt losers? J. R. Sibert. To be published in full in the Archives, 1980, 55.

A study of skeletal maturity in newly diagnosed juvenile diabetics. A. D. Edelsten. 
Pancreatic polypeptide antibodies in diabetic children. D. I. Johnston.

Enteroglucagon: aspects of its developmental physiology. A. Lucas.

Seckel's syndrome - a case report describing its association with marrow hypoplasia and immune deficiency. R. R. Gordon.

\section{British Paediatric Perinatal Group}

Problem of persistent ductus arteriosus in the low birthweight infant. D. R. S. Smith.

Effects of raising abdominal pressure on rib cage distortion and the work of breathing in preterm infants. P. Fleming.

Psychosocial stress and onset of premature labour. R. W. Newton.

A study to determine normal fetal heart rate and rhythm: coincidentally highlighting failings in antepartum fetal heart rate monitors. Jean $\mathbf{M}$. Richards.

24-hour tape recordings of ECG and respiration in the newborn infant with findings related to sudden death and unexplained brain damage in infancy. D.P. Southall. To be published in full in the Archives, $1980,55,7-16$.

\section{Assessing standards of perinatal care}

National uniformity in perinatal data collection: feasibility and desirability. I. Chalmers.

The Scottish perinatal mortality study. Gillian McIlwaine.

Lessons learned from a survey of newborn facilities in the south east region. H. R. Gamsu.

Open discussion on regional surveys of perinatal care.

\section{British Paediatric Radiology Group}

Polysynostoses (a group of skeletal dysplasias with possible inter-relationships). R. I. S. Gordon.

Copper deficiency syndrome. P. P. Franklyn.

Atlanto-axial joint in local and remote disease. G. M. Steiner.

Urinary tract stones in children. S. E. W. Smith.

Significance of the echo nephrogram. C. Metreweli. Necrotising enterocolitis. J. Virgee.

Fine needle cholangiography. H. Carty.

Diagnostic problems in bowel malrotation in the neonate. G. M. A. Hendry.

Initiation of respiration and onward progress of bowel gas in the neonate. J. B. Fawcitt.

Evaluating speech problems. A. R. Chrispin.

\section{British Association for Paediatric Nephrology}

Kidney failure in children. C. Chantler.

Abnormalities of lymphocyte function in minimal change nephrotic syndrome and focal glomerular sclerosis. S. J. Chapman.

Steroid toxicity and the eyes in children with nephrotic syndrome. J. T. Brocklebank.

Differential glomerular cellularity in the nephrotic syndrome with minimal change or focal glomerular sclerosis. N. Yoshikawa.

Lupus nephritis in childhood and adolescents. M. C. Morris.

Inherited aldosterone deficiency. M. H. Winterborn. Renal function after cardiopulmonary bypass surgery in children: the role of gentamicin. Susan Rigden.

Late metabolic acidosis: a reassessment of the definition. G. B. Haycock.

Effect of sterile vesico-ureteric reflux. Jean $M$. Smellie.

Detrusor instability and urinary symptoms in girls with vesico-ureteric reflux. C. M. Taylor.

\section{British Paediatric Gastroenterology Group}

Is the incidence of coeliac disease changing? J. Dossetor.

Combined gluten and cows' milk protein (CMP) intolerance. J. Watt.

Gluten intolerance in childhood-a community study. B. Fumigali.

Gluten challenge in treated coeliac disease. C. Coelho.

Lactose malabsorption, assessed by hydrogen breath test in acute gastroenteritis. A. J. Gardiner. Comparison of 3 feeds for prevention of delayed recovery after infantile gastroenteritis. P. D. Manuel.

Serum gastrin and plasma secretin levels in children with peptic ulcer. Y. Yamashiro.

Family study of protracted diarrhoea of infancy (PDI). F. M. Howard.

Acute phase proteins in childhood chronic inflammatory bowel disease. C. A. Campbell.

Hepatobiliary scanning in prolonged infantile jaundice: an assessment of ${ }^{99}$ technetium pyridoxylidine glutamate $\left({ }^{99} \mathrm{Tcm} P G\right)$. R. E. Jenner.

Serum bile acids in paediatric liver disease. C. A. R. Coelho.

Validation and application of a technique for simultaneously determining gastric emptying and secretion after a test meal in children. D. J. S. Cameron.

Intussusception in childhood. G. J. Frost. 
Subcellular fractionation studies of the intestinal mucosa in congenital sucrase-isomaltase deficiency (CSID). B. T. Cooper.

Yeast opsonisation in children with chronic diarrhoeal states. D. C. A. Candy. To be published in full in the Archives, 1980, 55.

\section{British Paediatric Oncology and Haematology Group}

Transcobalamin II deficiency with methymalonic acid excretion. P. Malleson.

Interaction of pyruvate kinase deficiency and $\beta$ thalassaemia genes in a Pakistani family. J. R. Y. Ross.

Combination chemotherapy for bone marrow relapse in childhood acute lymphoblastic leukaemia (ALL). Judith M. Chessells.

Effect of drug tolerance in childhood ALL. J. James. Survey of recent cases of acute nonlymphocytic leukaemia in childhood. C. Haworth.

Chronic myeloid leukaemia in childhood. A. Heppleston.

Busulphan lung in childhood. A. Oakhill.

Growth patterns in Wilms's tumours. Rosemary S.

Shannon.

Family reactions to successful treatment for children with leukaemia and nephroblastoma. J. Martin.

Cerebrospinal fluid methotrexate levels after high dose of intravenous infusion. A. Bosley.

Proptosis in childhood. A. Oakhill.

\section{British Paediatric Respiratory Group}

Physiological assessment of children with asthma. M. Silverman.

Exercise-induced asthma or hyperventilation-induced asthma? H. Kilham.
Respiratory function during adolescence (a longitudinal study). J. O. Warner.

Management of asthma in the preschool child. A. D. Milner.

Superior action of disodium cromoglycate solution over powder on the inhibition of exercise-induced bronchoconstriction in asthma. J. I. N. Chung.

Allergic bronchopulmonary aspergillosis complicating cystic fibrosis in childhood. M. J. Brueton. To be published in full in the Archives, 1980, 55.

Functional effects of neonatal respiratory disease; a simple classification. J. Stocks.

Apnoea monitoring of babies 'at risk' of SIDS. H. Simpson.

Tracheomalacia. M. P. Wailoo.

Chronic upper airways obstruction. D. Matthew.

Value of barium swallow in the investigation of mediastinal space-occupying lesions in infants. D. K. C. Cooper.

Ventilation/perfusion radioisotope lung scanning in children: clinical applications. P. Helms.

\section{BPA GENERAL SESSION}

Deprivation after nonaccidental injury-the paediatrician's role in its prevention. A. N. P. Speight. Accidents to children - an endemic of epidemic proportions. J. R. Sibert.

Child health in a day nursery. G. J. Frost.

Are child psychiatrists and medical social workers really necessary? B. Lask.

Individual therapy for very young handicapped children. J. Rubissow.

Emotional and educational disorders and diabetic control in children with diabetes. A. Gath. 